\title{
A hospital-based study of post-stroke aphasia: frequency, risk factors, and topographic representation
}

\author{
Eman M. Khedr" ${ }^{\text {** }}$ Mohamed A. Abbass², Radwa K. Soliman³, Ahmed F. Zaki ${ }^{2}$ Aymen Gamea², \\ Noha Abo El-Fetoh ${ }^{1}$ and Mahmoud A. Abdel-Aaal ${ }^{2}$
}

\begin{abstract}
Background and objective: The crude prevalence rate of stroke in Qena, Egypt, is high (922/100,000). For the first time, we estimate the frequency of aphasia following the first-ever ischemic stroke and its relationship to the site of lesion in Arabic-speaking countries.

Methods: The study was conducted on 180 acute or subacute ischemic stroke patients. Aphasia was diagnosed with the short form of the Boston Diagnostic Aphasia Examination after establishment of the cases (at least 10 days of stroke onset). Computed tomography and/or magnetic resonance imaging were performed for topographic localization of stroke, and routine laboratory investigations were done to evaluate the possible stroke risk factors.

Results: The frequency of post-stroke aphasia was recorded in 20\%, and atrial fibrillation (AF) represents a high-risk factor for ischemic stroke with aphasia. The following categories were observed: global aphasia in 50\%, motor aphasia in $27.7 \%$, sensory aphasia in $11.1 \%$, nominal aphasia in $2.8 \%$, and conductive aphasia in $8.3 \%$. Global aphasia was mainly associated with complete middle cerebral artery (MCA) territories infarction. Motor aphasia was associated mainly with frontal or frontoparietal operculum lesions as well as basal ganglionic lesions. Sensory aphasia was associated with temporal lobe lesions, inferior parietal lobe, and basal ganglia. Conductive aphasia showed lesions in the deep white matter of the frontal and parietal lobes. Anomic aphasia was associated with inferior parietal lobe lesion.

Conclusion: Our data are consistent with other reports as regards the frequency and risk factors of post-stroke aphasia. Atrial fibrillation represents a high-risk factor for ischemic strokes with aphasia. Global and motor aphasia are the major subtypes. The lesion locations are predictive of aphasia subtypes.
\end{abstract}

Keywords: Aphasia, Ischemic stroke, Hospital-based study, Boston Diagnostic Aphasia Examination test, National Institute of Health Stroke Scale

\section{Introduction}

Stroke is a major health problem in our country with the crude prevalence rate of stroke in Assiut and Qena being 963-922/ 100,000 [1, 2]. Most people survive a first stroke, although most are left with significant morbidity. Indeed, stroke is the most common cause of aphasia due to damage to the language network of the brain. These include Broca's and Wernicke's areas in the left hemisphere and homologous areas in the right side

\footnotetext{
* Correspondence: emankhedr99@yahoo.com

${ }^{1}$ Department of Neuropsychiatry, Assiut University Hospital, Assiut, Egypt Full list of author information is available at the end of the article
}

of the brain, the prefrontal and premotor areas in the frontal regions, and the lower part of the parietal region $[3,4]$. However, positron emission tomography (PET), functional magnetic resonance imaging (fMRI), and the magnetoencephalography showed that these areas in both hemispheres of the brain are activated specifically during language tasks, as well as activation of more distant areas of cortex [5].

It has been estimated that about $21-38 \%$ of stroke patients develop aphasia [6,7]. The reported annual incidence of post-stroke aphasia in Europe and the United States of America (USA) is 43-60 per 100,000 [8-10]. 
It has been reported that $20-40 \%$ of aphasias are of the global type, whereas the classic aphasia types, such as Broca's or Wernicke's aphasia, are found in a quarter of patients, and $10-15 \%$ of patients are unclassifiable according to traditional typologies during the acute stage of stroke [11]. Literature concerning the frequency of post-stroke aphasia, risk factors, and the relations between aphasia type and lesion location are limited, especially in Egypt.

The aim of this study is to estimate the frequency and risk factors of post-stroke aphasia, following the firstever ischemic stroke, and to study the relations of type of aphasia and lesions location of stroke Egypt. This is the first time that aphasia epidemiology is being studied in Arabic-speaking countries.

\section{Subjects and methods Study design}

The study was conducted on 180 ischemic strokes. They recruited consecutively from outpatient clinic during the period from first of October 2015 to end of March 2016. All patients were admitted to the Stroke Unit, Department of Neurology, South Valley University Hospital, Qena, Egypt. Stroke was defined according to World Health Organization (WHO) as a syndrome of rapidly developing clinical signs of focal or global disturbance of cerebral function, with symptoms lasting $24 \mathrm{~h}$ or longer with no apparent cause other than of vascular origin [12]. Each patient fulfilled the definition of stroke with or without aphasia and was documented by computed tomography of the brain (ischemic infarction) with acute or subacute onset (ranging from first day to 30 days after the onset) included. Exclusion criteria were as follows: comatose patients, patients with metabolic disorders, patients with history of head injury or neurological disease other than stroke, or patients with previous history of disturbed speech or hearing (e.g., deafness or deaf mute).

Clinical assessment after establishment of stroke was as follows (at least 10 days of stroke onset till the end of first month after the onset): a detailed history and neurological examination was performed for each patient. Motor strength and the language assessment section of the Hemispheric Stroke Scale (HSS) [13] were evaluated for each patient together with the National Institutes of Health Stroke Scale (NIHSS) [14] which assesses the functional disability of each patient. Aphasia was diagnosed with the Boston Diagnostic Aphasia Examination Test-short form.

Type of aphasia was diagnosed as follows [15]:

\section{Paraphasias}

Incorrect substitutions of words or parts of words

(a) Literal or phonemic paraphasias: similar sounds (e.g., "sound" for "found" or "fen" for "pen") (b) Verbal or semantic paraphasias: word substituted for another form same semantic class (e.g., "fork" for "spoon" or "pen" for "pencil").

2. Broca's aphasia

Motor aphasia, problems with output;

understanding intact, nonfluent, hesitant, labored,

and paraphasic speaking, vocabulary and

confrontation naming is severely impaired, and

writing is similarly affected

3. Anomic aphasia

Mild motor aphasia, problem with output;

understanding intact, word-finding difficulties, or mild articulatory errors (often called verbal apraxia)

4. Transcortical motor aphasia

Stroke is located in the frontal lobe, anterior or superior to Broca's area or in the subcortical region deep to Broca's area, characterized by nonfluent (reduced rate of speech and limited language output), good comprehension and good repetition.

5. Wernicke's aphasia

Sensory aphasia, problem with input, fluent speech with severe comprehension deficit, poor repetition and often unintelligible jargon; reading is similarly affected and associated with marked paraphasias and neologisms.

6. Transcortical sensory aphasia

Watershed stroke isolating the perisylvian speech structures (Broca's and Wernicke's areas) from the posterior brain, characterized by fluent speech (neologisms) and poor comprehension and good repetition (possibly echolalia).

7. Conduction aphasia

Stroke of the parietal operculum (arcuate fasciculus) or insula or deep to the supramarginal gyrus characterized by disproportional impairment in repeating spoken languages and literal paraphasias with "targeting" of words (until getting the right one).

8. Global aphasia

Motor and sensory aphasia, problem with input and output, no communication even with gestures and no speech or only stereotypical repetitive utterances, reading and writing affected, and generally involve the entire middle cerebral artery (MCA) region with moderate to severe impairment of language of all language function.

Computed tomography (CT) and/or magnetic resonance imaging (MRI) were performed for topographic localization of stroke.

Echocardiography and electrocardiography and routine laboratory investigations were performed to evaluate the possible risk factors for aphasia. 


\section{Statistical analysis}

The data were analyzed using SPSS 16.0 software. Qualitative data were described in frequency using percentage (\%). Continuous variables were expressed in mean \pm standard deviation (SD). Comparative statistical analysis between variables was done using chi-square for qualitative data and independent $t$ test for continuous variables. A value of $P<0.05$ was considered statistically significant.

\section{Results}

Thirty six patients out of 180 ischemic stroke patients (20\%) had aphasia. The mean age \pm SD for patients with aphasia in ischemic stroke was $55.8 \pm 10.6$ compared with $56.29 \pm 9.92$ years for non-aphasic patients $(P>$ $0.05)$. The mean total NIHSS \pm SD for patients with ischemic stroke with aphasia was $18.36 \pm 2.88$ which was significantly higher than in patients without aphasia $(6.97 \pm 3.0)(P$ value $=0.00)$. There was no significant association between aphasia and sex. Only two patients with aphasia were left handed and had right ischemic infarction (Table 1).

There were no significant differences between patients with aphasia and patients without aphasia in any of the risk factors associated with stroke except in ischemic heart disease and atrial fibrillation (IHD and AF) with a significantly higher percentage of both factors in aphasic patients (Table 2).

Interestingly, we found the commonest type of aphasia was global aphasia $(n=18(50 \%)$. Other types of aphasia were as follows: motor aphasia $(n=10$ $(27.7 \%))$, sensory aphasia $(n=4(11.1 \%))$, nominal aphasia $(n=1(2.8 \%))$, and conductive aphasia $(n=3$ $(8.3 \%))$.

Seventeen patients out of $36(47.2 \%)$ patients performed MRI brain study, and the remaining cases underwent CT brain study. Neuroimaging details of each type of aphasia are shown in Table 3.

Only two patients (5.5\%) in our population had CT evidence of right-sided infarction and both patients were left handed, suggestive of right hemisphere language lateralization.

\section{Discussion}

Aphasia is one of the most important causes of disability in post-stroke cases. This is the first study in Arabic-speaking population aimed to estimate the frequency and risk factors of aphasia following the firstever ischemic stroke Egyptian patients. Estimations of the frequency of pure aphasia types vary from 20$30 \%[16,17]$ to almost $100 \%$ [18]. In the present study, the incidence of aphasia following first ever ischemic stroke cases was $20 \%$ which was similar to others $[9,19-23]$. It was lower than that reported by Pedersen et al. [24], Kauhanen et al. [25] and Engelter et al. [8], all of whom reported an incidence above $30 \%$, while Berthier et al. [10] reported a very high incidence of $80 \%$. Conversely, a very low incidence (10.3\%) was reported by Naess et al. [26]. The differences between studies may relate to the inclusion criteria as some reported the incidence after first ever stroke while others reported the incidence after single or multiple strokes.

In the present study, there was no significant difference between male and females in relation to the presence or absence of aphasia. The educational level had no relation to the occurrence of aphasia in agreement with other studies [27, 28].

Language function is almost exclusively the domain of the left hemisphere, except for $35 \%$ of left handers $(3 \%$ of population) who use the right hemisphere for language function [29]. In the strongly left-handed subjects, $73.7 \%$ had left-side language cerebral dominance, $15.8 \%$ had bilateral cerebral representation, and $10.5 \%$ had right-side cerebral language dominance [29]. In the present study, only two left handed patients had aphasia one of them had right frontoparietal operculum and the insula (MCA territory) and the other had massive right frontoparietal infarction (MCA occlusion) that confirm the previous results.

Patients with atrial fibrillation (AF) tended to present more often with aphasia ( 22.2 vs. $7.6 \%)$ and were more severely impaired. Similar results have been reported by several other groups $[8,22,30-32]$. AF is associated with

Table 1 Demographical data of all cases of stroke

\begin{tabular}{|c|c|c|c|c|}
\hline Variable & Total ischemic stroke (180 cases ) & Patients with aphasia, 36 (20\%) & Patients without aphasia, 144 (80\%) & $P$ value \\
\hline Age (mean $\pm S D)$ & $56.1 \pm 1.5$ & $55.8 \pm 10.6$ & $56.29 \pm 9.92$ & 0.805 \\
\hline $\operatorname{Sex}(M / F)$ & $84 / 96$ & $17 / 19$ & $67 / 77$ & 0.940 \\
\hline Handedness (RT/LT) & $172 / 8$ & $34 / 2$ & $138 / 6$ & 0.718 \\
\hline $\begin{array}{l}\text { Duration of stroke onset (days) } \\
\text { (the time passed from the onset } \\
\text { to be enrolled) (mean } \pm \text { SD) }\end{array}$ & $28.1 \pm 22.6$ & $23.2 \pm 21.1$ & $10.9 \pm 9.1$ & 0.0001 \\
\hline $\begin{array}{l}\text { Education: literate/illiterate number } \\
\text { and percent }\end{array}$ & $127 / 53(70.5 \% / 29.5 \%)$ & $26 / 10(72.2 / 27.8 \%)$ & $101 / 43(70.1 / 29.9 \%)$ & 0.806 \\
\hline
\end{tabular}


Table 2 Risk factors of 180 ischemic stroke patients in relation to the presence or absence of aphasia Parameter

\begin{tabular}{lllll}
\hline Parameter & $\begin{array}{l}\text { Total number of cases } \\
(180 \text { cases }), N \text { (percent) }\end{array}$ & $\begin{array}{l}\text { Patients with aphasia } \\
(36 \text { cases }), N \text { (percent) }\end{array}$ & $\begin{array}{l}\text { Patients without aphasia } \\
(144 \text { cases), N (percent) }\end{array}$ \\
\hline HTN & $52(28.9 \%)$ & $8(22.2 \%)$ & $44(30.6 \%)$ & $40(27.8 \%)$ \\
DM & $53(29.4 \%)$ & $13(36.1 \%)$ & $20(13.9 \%)$ & 0.324 \\
Old age & $24(13.3 \%)$ & $4(11.1 \%)$ & $31(21.5 \%)$ & 0.327 \\
Smoking & $41(22.7 \%)$ & $10(27.8 \%)$ & $27(18.8 \%)$ & 0.878 \\
Obesity & $33(18.3 \%)$ & $6(16.7 \%)$ & $16(11.1 \%)$ & 0.424 \\
Dyslipidemia & $24(13.3 \%)$ & $8(22.2 \%)$ & $8(5.6 \%)$ & 0.773 \\
Substance abuse & $10(5.6 \%)$ & $2(5.6 \%)$ & $7(4.9 \%)^{*}$ & $13(9 \%)$ \\
IHD & $15(8.3 \%)$ & $8(22.2 \%)$ & $11(7.6 \%)^{*}$ & 0.079 \\
Hyperuricemia & $15(8.3 \%)$ & $2(5.6 \%)$ & $8(22.2 \%)$ & $0.061^{*}$ \\
AF & $19(10.6 \%)$ & $0.011^{*}$ \\
\hline
\end{tabular}

Hypertension: HTN , Diabetes mellitus :DM, ischemic heart disease: IHD, atrial fibrillation: AF, number: $N$ *Statistically significant

**Statistically highly significant

a higher risk of ischemic cerebrovascular events and more severe ischemic strokes [33-35].

Epidemiological studies have found increased risk of stroke associated with other risk factors, including cardiovascular abnormalities such as coronary artery disease (CAD), heart failure (HF), and atrial fibrillation (AF) [36]. In the Framingham study, the age-adjusted 2-year incidence of stroke was more than double in the presence of CAD, more than triple in the presence of hypertension, more than quadruple in the presence of HF, and nearly quintupled when AF was present [37]. In the present study, we also found a significant association between IHD and poststroke aphasia which may be indirectly related to association between IHD and AF.

In the present study, global aphasia was the most common (50.5\%) followed by motor $(27.8 \%)$ and sensory aphasia (11.1\%). Both conductive and nominal aphasia were uncommon and were found in only $8.3 \%$ and $2.8 \%$ respectively. Our results are similar to many other studies which found that both global and motor aphasia are the major subtypes [30, 37-39].

Most patients with global aphasia in our study had extensive cortical and subcortical damage in the whole region supplied by the MCA. Thus, both Broca's and Wernicke's areas, along with underlying white matter and basal ganglia connections, were damaged. However, a few cases with global aphasia showed only localized lesions either involving the frontal or the parietal lobe. The presence of associated hypo-perfusion in the adjacent regions, which could have been compensated from other major arterial territories or collateral circulation, might explain the global aphasia despite the absence of

Table 3 Radiological site of lesions of 36 cases of ischemic stroke with aphasia

\begin{tabular}{|c|c|c|}
\hline Types of aphasia & $\begin{array}{l}\text { Number of } \\
\text { cases (\%) }\end{array}$ & Site of each lesion \\
\hline Global aphasia & $18(50 \%)$ & $\begin{array}{l}12 \text { cases total left MCA infarction } \\
1 \text { case total right MCA infarction } \\
2 \text { cases left frontal infarctions, involves the cortex and the subcortical WM, (MCA territory) } \\
2 \text { cases left parietal infarction, involves the cortex and the subcortical WM, (MCA territory) } \\
1 \text { case left parietal-occipital infarction }\end{array}$ \\
\hline $\begin{array}{l}\text { Broca's } \\
\text { (motor aphasia) }\end{array}$ & $10(27.8 \%)$ & $\begin{array}{l}3 \text { cases left frontal operculum and the anterior insula } \\
1 \text { case right frontoparietal operculum and the insula (MCA territory) } \\
3 \text { cases left frontoparietal infarction, involves the cortex and the subcortical WM, with extension to the premotor, } \\
\text { motor, and sensory areas at the lateral surface (MCA territory) } \\
3 \text { case left basal ganglionic infarction (putamen and lenticulocapsular region-MCA territory, lateral } \\
\text { lenticulostriate). }\end{array}$ \\
\hline $\begin{array}{l}\text { Wernicke's } \\
\text { (sensory aphasia) }\end{array}$ & $4(11.1 \%)$ & $\begin{array}{l}2 \text { cases left temporoparietal infarction, involves the cortex and the subcortical WM, (MCA territory) } \\
1 \text { case left temporal infarction, involves the cortex and the subcortical WM, (MCA territory). } \\
1 \text { case left basal ganglionic infarction, lentiform nucleus (MCA territory, lateral lenticulostriate) }\end{array}$ \\
\hline $\begin{array}{l}\text { Conductive } \\
\text { aphasia }\end{array}$ & $3(8.3 \%)$ & 3 cases diffuse small vessels ischemia (periventricular and deep WM) \\
\hline Nominal aphasia & $1(2.8 \%)$ & Left angular gyrus infarction (MCA territory) \\
\hline
\end{tabular}


diffuse detectable lesions on CT. Perfusion imaging, however, may be required in order to support this postulation. Additionally, different neuroimaging and transcranial magnetic stimulation (TMS) studies further showed that premotor and motor areas can be linked to speech perception $[40,41]$ as well as speech production $[42,43]$. Therefore, lesions in such regions may affect the language network and contribute to aphasic deficits whether sensory, motor, or global. This is, however, less likely in our cases since the main perception center was preserved.

In the present study, patients who presented with motor aphasia exhibited lesions involving the left frontal operculum and the insula. Some cases showed, in addition, extension to the parietal operculum whereas others showed more diffuse extension to the left dorsolateral frontal lobe to involve the motor and premotor areas. Aphasia in such patients is explained by injury of the inferior frontal gurus encompassing pars opercularis and pars triangularis (Broca's area) thus causing the classic Broca's (motor) aphasia $[44,45]$. The extension to the parietal operculum may also partially contribute to the speech production deficits, as it has been shown that cortical lesions of the inferior parietal lobe can cause repetition impairment [46]. Additionally, involvement of the enclosed white matter, the arcuate fasciculus, can cause repetition impairment [47]. As mentioned above, a number of studies showed that premotor and motor areas can be linked to speech production [42, 43]. Therefore, lesions in such regions may further contribute to the motor aphasia.

Previous studies investigated the role of basal ganglia region as well as the thalamus in language production [48-50]. Despite the contradictory views in this concern, the majority appear to suggest that lesions involving these regions affect the fluency of the speech [49] rather than comprehension [51]. Our data is consistent with this, as we found three cases with lenticulocapsular lesions presented with motor aphasia and only one patient with lenticular infraction presented with sensory aphasia. Disruption of basal ganglionic networks to any of the cortical speech area could be responsible for the aphasic deficits in those patients. In accordance with this hypothesis, other studies revealed a direct functional connectivity between the putamen and Broca's area [50]. Furthermore, a direct anatomical pathway between Putamen and inferior frontal lobe [52, 53], as well as between the putamen and the motor and premotor regions, have been reported using diffusion tensor imaging [54], demonstrating the role of basal ganglia, particularly, the putamen in the process of speech production.

Patients in our study with sensory aphasia had lesions involving mainly the left temporal lobe, with some cases having involvement of the inferior parietal lobe. Damage of the Wernicke area (superior temporal gyrus) is most probably responsible for the sensory aphasia in those patients [55]. These mentioned data are partially matched to some extent with previous results [56].

We also had three cases of conductive aphasia with a picture of extensive small vessel ischemic changes and involvement of the periventricular and deep white matter (WM) of both frontal and parietal lobes bilaterally. This is most likely due to interruption of the connection between the anterior and posterior speech areas secondary to an injury of the long segment of the arcuate fasciculus [47], hence a disconnection syndrome between the Broca's and Wernicke's areas [55]. Dwidar et al. conducted a study on 70 acute ischemic stroke patients with aphasia affecting the dominant hemisphere; they reported that aphasia is not a pure cortical function as deep periventricular white matter and insular area in the dominant hemisphere play an important role in many language tasks [57].

One patient in the present study had anomic aphasia with ischemic lesions in the left posterior inferior parietal lobe. Many brain regions in the literature have been reported to be related to the anomia. Inconsistent with our results, other studies, however, showed anomia is more common with lesions to other regions such as occipital lobe [58], occipitotemporal area (Brodmann area 37), and the premotor area of the frontal lobe [59], as well the thalamus $[49,60]$, and less likely related to the striatocapsular region [51].

Main limitations of this study are the small sample size and lack of MRI study in some cases.

\section{Conclusions}

Despite remarkable differences between western languages and Arabic, the frequency and risk factors of post-stroke aphasia as well as lesion localization are similar. Global and motor aphasia were the major subtypes.

Our data are consistent with other reports in most of the cases which showed that the lesion locations were compatible with and predictive of the type of aphasia $[35,37,58,60]$, yet there was a wide degree of overlap between the distribution pattern of brain damage and the aphasia type with some unexpected findings.

\section{Abbreviations \\ AF: Atrial fibrillation; CT: Computed tomography; CAD: Coronary artery disease; DM: Diabetes mellitus; fMRI: Functional magnetic resonance imaging; HF: Heart failure; HSS: Hemispheric Stroke Scale; IHD: Ischemic heart disease; MRI: Magnetic resonance imaging; MCA: Middle cerebral artery; NIHSS: National Institutes of Health Stroke Scale; PET: Positron emission tomography; SD: Standard deviation; USA: United States of America; WM: White matter; WHO: World Health Organization}

Acknowledgements

Not applicable.

\section{Authors' contributions}

EMK, MAA, AF, AG, and MA contributed to study concept and design, acquisition of data, draft and revision of the report, statistical analyses, and interpretation of data. NAE, AFZ, MAA, and AG contributed to the case recruitments, acquisition of data, and statistical analyses. RKS contributed to 
the interpretation of neuroradiology data and draft and revision of the report. EMK, RKS, and NAE contributed to the editing of this report. All authors read and approved the final manuscript.

\section{Funding}

Not applicable.

\section{Ethics approval and consent to participate}

An informed consent was obtained from all the patients before participating in the study. The protocol was approved in January 2014 by the South Valley Medical School.

Ethical Review Board and all participants or relatives gave written informed consent before participation in the study. The confidentiality of the patients' information was maintained during all the steps of the study.

\section{Consent for publication}

Not applicable.

\section{Competing interests}

The authors declare that they have no competing interests.

\section{Author details}

'Department of Neuropsychiatry, Assiut University Hospital, Assiut, Egypt. 2Department of Neuropsychiatry, South Valley University Hospital, Qena, Egypt. ${ }^{3}$ Department of Radiology, Faculty of Medicine, Assiut University Hospital, Assiut, Egypt.

Received: 30 July 2019 Accepted: 4 November 2019 Published online: 31 December 2019

\section{References}

1. Khedr EM, Elfetoh NA, Al Attar G, Ahmed MA, Ali AM, Hamdy A, Kandil MR, Farweez $\mathrm{H}$. Epidemiological study and risk factors of stroke in Assiut Governorate, Egypt: community-based study. Neuroepidemiology. 2013; 40(4):288-94.

2. Khedr EM, Fawi G, Abdela M, Mohammed TA, Ahmed MA, El-Fetoh NA, Zaki AF. Prevalence of ischemic and hemorrhagic strokes in Qena Governorate, Egypt: community-based study. J Stroke Cerebrovasc Dis. 2014;23(7):1843-8.

3. Frey S, Campbell JS, Pike GB, Petrides M. Dissociating the human language pathways with high angular resolution diffusion fiber tractography. J Neurosci. 2008;28:11435-44.

4. Vigneau M, Beaucousin V, Hervé PY, Duffau H, Crivello F, Houdé O, Mazoyer B, Tzourio-Mazoyer N. Meta-analyzing left hemisphere language areas: phonology, semantics, and sentence processing. Neuroimage. 2006:30: 1414-32.

5. Hillis AE. Aphasia: progress in the last quarter of a century. Baltimore: John Hopkins University School of Medicine; 2007. (Supported by NIH (NIDCD) from AAN Enterprises, Inc.)

6. Wade DT, Hewer RL, David RM, Enderby PM. Aphasia after stroke: natural history and associated deficits. J Neurol Neurosurg Psychiatry. 1986;49(1):11-6.

7. Nadamuni S. Researchers identify stroke subtypes in India. Lancet. 2002;359:500

8. Engelter ST, Gostynski M, Papa S, Frei M, Born C, Ajdacic-Gross V, Gutzwille F, Lyrer PA. Epidemiology of aphasia attributable to first ischemic stroke: incidence, severity, fluency, etiology, and thrombolysis. Stroke. 2006;37: 1379-84.

9. Dickey L, Kagan A, Lindsay MP, Fang J, Rowland A, Black S. Incidence and profile of inpatient stroke-induced aphasia in Ontario, Canada. Archives of Physical Medicine and Rehabilitation. 2010;91:196-202.

10. Berthier ML, Pulvermüller F, Dávila G, Casares NG, Gutiérrez A. Drug therapy of post-stroke aphasia: a review of current evidence. Neuropsychol Rev. 2011;21(3):302-17.

11. Pedersen PM, Vinter K, Olsen TS. Aphasia after stroke: type, severity and prognosis. The Copenhagen aphasia study. Cerebrovasc Dis. 2004;17:35-43.

12. Wolf PA, Kannel WB, Dawber TR. Prospective investigations: the Framingham study and the epidemiology of stroke. Adv Neurol. 1978;19:107-20.

13. Adams RJ, Meador KJ, Sethi KD, Grotta JC, Thomson DS. Graded neurologic scale for use in acute hemispheric stroke treatment protocols. Stroke. 1987; 18:665-9.
14. Brott T, Adams HP Jr, Olinger CP, Arler JR, Barsan WG, Biller J, Spilker J, Holleran R, Eberle R, Hertzberg V, et al. Measurements of acute cerebral infarction: a clinical examination scale. Stroke. 1989;20:864-70.

15. Teasell R and Hussein N (2018) 2.Clinical consequences of stroke [evidence based review of stroke rehabilitation] (www.ebrsr.com)

16. Prins RS, Snow CE, Wagenaar E. Recovery from aphasia: spontaneous speech versus language comprehension. Brain and language. 1978;6:192-211.

17. Albert ML, Olber LK, Goodglass H. Helm NA. Alexander MP. Clinical aspects of dysphasia. Wien/ New York. Springer Verlag: Rubens AB; 1981.

18. De Renzi $E$, Faglioni P, Ferrari $P$. The influence of sex and age on the incidence and type of aphasia. Cortex. 1980;16(4):627-30.

19. Erin L, Erin C. Aphasia: a description of the incidence and management in the acute hospital setting/ lournal. Asia Pacific Journal of Speech, Language and Hearing. 2004;9(2):129-36.

20. Laska AC, Hellblom A, Murray V, Kahan T, Von Arbin M. Aphasia in acute stroke and relation to outcome. Journal of Internal Medicine. 2001;249(5):413-22.

21. Law J, Huby G, Irving A-M, Pringle A-M, Conochie D, Haworth C, Burston A. Reconciling the perspective of practitioner and service user: findings from the Aphasia in Scotland Study. Int. J. Lang. Commun. Disord. 2010;45(5):551-60.

22. Tsouli S, Kyritsis AP, Tsagalis G, Virvidaki E, Vemmos KN. Significance of aphasia after first-ever acute stroke: impact on early and late outcomes. Neuroepidemiology. 2009;33:96-102.

23. Vidović M, Sinanović O, Sabaskić L, Haticić A, Brkić E. Incidence and types of speech disorders in stroke patients. Acta Clin. Croat. 2011;50:491-4.

24. Pedersen PM, Jørgensen HS, Nakayama H, Raaschou HO, Olsen TS. Aphasia in acute stroke: incidence, determinants, and recovery. Ann. Neurol. 1995;38: 659-566.

25. Kauhanen ML, Korpelainen JT, Hiltunen P, Määttä R, Mononen H, Brusin E, Sotaniemi KA, Myllylä W. Aphasia, depression, and non-verbal cognitive impairment in ischaemic stroke. Cerebrovasc. Dis. 2000;10: 455-61.

26. Naess H, Hammersvik L, Skeie GO. Aphasia among young patients with ischemic stroke on long-term follow-up. J Stroke Cerebrovasc. Dis. 2009; 18(4):247-50.

27. Connor LT, Obler LK, Tocco M, Fitzpatrick PM, Albert ML. Effect of socioeconomic status on aphasia severity and recovery. Brain Lang. 2001; 78(2):254-7

28. Lazar RM, Speizer AE, Festa JR, Krakauer JW, Marshall RS. Variability in language recovery after first-time stroke. J. Neurol. Neurosurg. Psychiatry. 2008:79(5):530-4.

29. Khedr EM, Hamed E, Said A, Basahi J. Handedness and language cerebral lateralization. Eur J Appl Physiol. 2002;87(4-5):469-73.

30. Croquelois A, Bogousslavsky J. Stroke aphasia: 1,500 consecutive cases Cerebrovasc Dis. 2011:31(4):392-9.

31. Fennis TF, Compter A, van den Broek MW, Koudstaal PJ, Algra A, Koehler PJ. Is isolated aphasia a typical presentation of presumed cardioembolic transient ischemic attack or stroke? Cerebrovasc Dis. 2013:35:337-40.

32. Lamassa M, Di Carlo A, Pracucci G, Basile AM, Trefoloni G, Vanni P, Spolveri S, Baruffi MC, Landini G, Ghetti A, Wolfe CD, Inzitari D. Characteristics, outcome, and care of stroke associated with atrial fibrillation in Europe: data from a multicenter multinational hospital-based registry (The European Community Stroke Project). Stroke. 2001;32(2):392-8.

33. Aguilar MI, Hart R, Pearce LA. Oral anticoagulants versus antiplatelet therapy for preventing stroke in patients with non-valvular atrial fibrillation and no history of stroke or transient ischemic attacks. Cochrane Database. Syst Rev. 2007;3:CD006186.

34. Wolf PA, Abbott RD, Kannel WB. Atrial fibrillation: a major contributor to stroke in the elderly. The Framingham Study. Arch Intern Med. 1987;147:1561-4.

35. Rosamond W, Flegal K, Furie K, Go A, Greenlund K, Haase N, Hailpern SM, Ho M, Howard V, Kissela B, Kittner S, Lloyd-Jones D, McDermott M, Meigs J, Moy C, Nichol G, O'Donnell C, Roger V, Sorlie P, Steinberger J, Thom T, Wilson M, Hong Y; American Heart Association Statistics Committee and Stroke Statistics Subcommittee. Heart disease and stroke statistics - 2008 update: a report from the American Heart Association Statistics Committee and Stroke Statistics Subcommittee. Circulation 2008; 117:e25-e146.

36. Wolf PA, Abbott RD, Kannel WB. Atrial fibrillation as an independent risk factor for stroke: the Framingham Study. Stroke. 1991;22:983-8.

37. Hayward RW, Naeser MA, Zatz LM. Cranial computed tomography in aphasia: correlation of anatomical lesions with functional deficits. Radiology. 1977;123(3):653-60. 
38. Godefroy O, Dubois C, Debachy B, Leclerc M, Kreisler A. Lille Stroke Program. Vascular aphasias: main characteristics of patients hospitalized in acute stroke units. Stroke. 2002;33(3):702-5.

39. Bohra V, Khwaja GA, Jain S, Duggal A, Ghuge W, Srivastava A. Clinicoanatomical correlation in stroke related aphasia. Ann. Indian Acad. Neurol. 2015;18(4):424-9.

40. Meister IG, Wilson SM, Deblieck C, Wu AD, lacoboni M. The essential role of premotor cortex in speech perception. Current Biology. 2007;17(19):1692-6.

41. Lacoboni M. The role of premotor cortex in speech perception: evidence from fMRI and rTMS. Journal of Physiology-Paris. 2008;102(1-3):31-4.

42. Meinzer M, Lindenberg R, Sieg MM, Nachtigall L, Ulm L, Flöel A. Transcranial direct current stimulation of the primary motor cortex improves wordretrieval in older adults. Frontiers in aging neuroscience. 2014;6:253.

43. Benjamin ML, Towler S, Garcia A, Park H, Sudhyadhom A, Harnish S, McGregor KM, Zlatar Z, Reilly JJ, Rosenbek JC, Gonzalez Rothi L, Crosson B. A behavioral manipulation engages right frontal cortex during aphasia therapy Neurorehabil Neural. Repair. 2014;28(6):545-53.

44. Broca PP. Loss of speech, chronic softening and partial destruction of the anterior left lobe of the brain. Trans. revised. 2003.

45. Dronkers NF. A new brain region for coordinating speech articulation. Nature. 1996;384(6605):159-61.

46. Quigg M, Geldmacher DS, Elias WJ. Conduction aphasia as a function of the dominant posterior perisylvian cortex. Report of two cases. J. Neurosurg. 2006;104(5):845-648.

47. Catani M, Jones DK. Perisylvian language networks of the human brain. Annals of Neurology. 2005;57(1):8-16.

48. Radanovic M, Mansur LL. Aphasia in vascular lesions of the basal ganglia: a comprehensive review. Brain and language. 2017;173:20-32

49. Zenon A, Olivier E. Contribution of the basal ganglia to spoken language: is speech production like the other motor skills? Behavioral and Brain Sciences. 2014;37(6):576.

50. Booth JR, Wood L, Lu D, Houk JC, Bitan T. The role of the basal ganglia and cerebellum in language processing. Brain research. 2007;1133:136-44.

51. Kuljic-Obradovic DC. Subcortical aphasia: three different language disorder syndromes? European Journal of Neurology. 2003;10(4):445-8.

52. Lehéricy S, Ducros M, Van De Moortele PF, Francois C, Thivard L, Poupon C, Swindale N, Ugurbil K, Kim DS. Diffusion tensor fiber tracking shows distinct corticostriatal circuits in humans. Annals of Neurology. 2004;55(4):522-9.

53. Ford A, Triplett W, Sudhyadhom A, Gullett J, McGregor K, Fitzgerald DB, Mareci T, White K, Crosson B. Broca's area and its striatal and thalamic connections: a diffusion-MRI tractography study. Frontiers in Neuroanatomy. 2013;7:8.

54. Leh SE, Petrides M, Strafella AP. The neural circuitry of executive functions in healthy subjects and Parkinson's disease. Neuropsychopharmacology. 2010; 35(1):70-85.

55. Geschwind N. Disconnexion syndromes in animals and man. In: Selected papers on language and the brain. Springer, Dordrecht. 1974:105-236

56. Emam A. The diagnostic role of neuroradiology in dysphasic patients. Cairo: Ain Shams University; 2003

57. Dwidar AAZ, Alloush TK, Abou El-Ella MY, Ahmed NSE, Maher KM, Nada MAM, Ibrahim MH. Clinical and radiological localization of language dysfunctions in acute ischemic stroke. Open Journal of Medical Imaging. 2014;4:80-5.

58. Kraft A, Grimsen C, Kehrer S, Bahnemann M, Spang K, Prass M, Irlbacher K, Köhnlein M, Lipfert A, Brunner F, Kastrup A, Fahle M, Brandt SA. Neurological and neuropsychological characteristics of occipital, occipitotemporal and occipito-parietal infarction. Cortex. 2014;56:38-50

59. Foundas AL, Daniels SK, Vasterling JJ. Anomia: case studies with lesion localization. Neurocase. 1998;4(1):35-43.

60. ÖZTÜRK Ş, Fahrettin EG, Ekmekci H. Language disorders due to posterior system strokes-an ignored dysfunction. Nöro Psikiyatri Arşivi. 2014;51(4):313.

\section{Publisher's Note}

Springer Nature remains neutral with regard to jurisdictional claims in published maps and institutional affiliations.

\section{Submit your manuscript to a SpringerOpen ${ }^{\circ}$ journal and benefit from:}

- Convenient online submission

- Rigorous peer review

- Open access: articles freely available online

High visibility within the field

- Retaining the copyright to your article

Submit your next manuscript at $\boldsymbol{\nabla}$ springeropen.com 